\title{
Bilateral presumed astrocytic hamartomas in a patient with retinitis pigmentosa
}

This article was published in the following Dove Press journal:

Clinical Ophthalmology

23 November 2011

Number of times this article has been viewed

\author{
Michael Kinori' \\ Iris Moroz ${ }^{1,2}$ \\ Ygal Rotenstreich ${ }^{1,2}$ \\ Hagith Yonath ${ }^{2,3}$ \\ Ido Didi Fabian' \\ Vicktoria Vishnevskia-Dai ${ }^{1,2}$ \\ 'Department of Ophthalmology, \\ Chaim Sheba Medical Center, \\ Tel Hashomer, Israel; ${ }^{2}$ Sackler \\ Faculty of Medicine, Tel Aviv \\ University, Tel Aviv, Israel; ${ }^{3}$ Danek \\ Gertner Genetic Institute and \\ Internal Medicine A, Chaim \\ Sheba Medical Center, Tel \\ Hashomer, Israel
}

\begin{abstract}
Retinal astrocytic hamartomas are benign intraocular tumors classically associated with phacomatoses. Their appearance in isolation is rare. An association between astrocytic hamartomas and retinitis pigmentosa (RP) has been described previously, but controversy still exists regarding the precise nature of these lesions in RP patients. The authors present a case report of a 24-year-old male with RP and multiple bilateral lesions clinically consistent with retinal astrocytic hamartomas. Optical coherence tomography revealed multiple bilateral hyper-reflective intraretinal masses, loss of retinal architecture, intralesional calcifications, and prominent optical posterior shadowing. Comprehensive systemic evaluation was negative for phacomatoses. However, given that a biopsy was not performed, the diagnosis of optic nerve head drusen could not be excluded.
\end{abstract}

Keywords: giant drusen, optic nerve head drusen, optical coherence tomography, intraocular tumor

\section{Introduction}

Retinal astrocytic hamartoma is a benign intraocular tumor that appears as a yellow-gray mass, frequently associated with minimally dilated retinal vessels, fine retinal traction, and glistering intrinsic calcifications. ${ }^{1-3}$ Tumor characteristics, appreciable using optical coherence tomography (OCT), include the gradual transition from a normal retina to a hyper-reflective intraretinal mass, anterior surface hyper-reflectivity, retinal disorganization, discrete internal moth-eaten optically empty spaces (representing intralesional calcification or intratumoral cavities), and optical shadowing posterior to the tumor. ${ }^{1}$ These tumors, classically associated with tuberous sclerosis or neurofibromatosis, are often diagnosed based on the characteristic ophthalmoscopic features without the need for biopsy. ${ }^{2}$ Isolated ocular appearance of these tumors without evidence of phacomatoses is rare.

\section{Case report}

The authors present a case of a 24-year-old Georgian male with abnormal retinal findings consisting of multiple bilateral retinal astrocytic hamartomas or "giant drusen" (Figure 1A). Other peripheral retinal findings were narrow retinal vessels and sparse hypopigmented lesions on the nasal side of the retina in both eyes. No overt "bone spicules" were detected. The macular area in both eyes showed general thinning (central retinal thickness of $142 \mu \mathrm{m}$ in the right eye and $147 \mu \mathrm{m}$ in the left, not shown). There was no evidence of cystoid macular edema. The best-corrected visual acuity
Correspondence: Michael Kinori Department of Ophthalmology, Chaim Sheba Medical Center,

Tel Hashomer 52621, Israel

Tel +972 35302874

Fax +972 35302822

Email mkinori@hotmail.com 


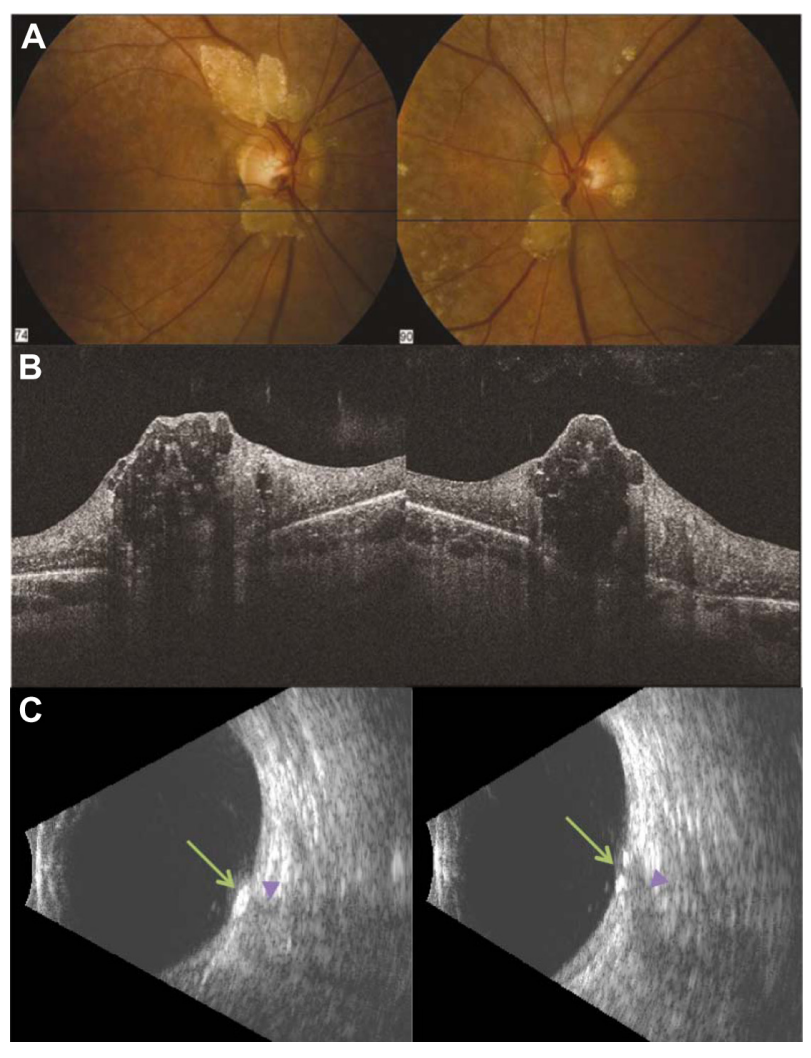

Figure I (A) Bilateral multiple peripapillary presumed astrocytic hamartomas. Multiple small lesions distant from the optic nerve are seen in the left eye. Lines represent planes of optical coherence tomography (OCT) images. (B) Bilateral OCT from the patient showing gradual transition from a normal retina to the hyper-reflective intraretinal mass, anterior surface hyper-reflectivity, and loss of normal retinal organization. Note the characteristic moth-eaten pattern that occurs in the upper third of the tumor. (C) B-mode ultrasound echography of both eyes showing hyperechogenic masses (green arrows) with posterior shadowing (purple arrowheads).

(BCVA) was 20/50 in the right eye and 20/400 in the left eye. Visual field analysis (static automated perimetry, 24-2, stimulus III for the right eye and stimulus $\mathrm{V}$ for the left eye) showed general peripheral reduction, mostly in the temporal side in both eyes. OCT (Cirrus HD-OCT, v 5.1.1.6; Carl Zeiss Meditec, Jena, Germany) of the optic nerves revealed features characteristic of astrocytic hamartomas (Figure 1B). B-scan ultrasonography revealed hyperechogenic lesions around both optic nerves with posterior shadowing (Figure 1C). Family history was negative for phacomatoses. Comprehensive physical and dermatological examination did not reveal clinical features of phacomatoses. On investigation, brain magnetic resonance imaging and audiometry were normal, and abdominal ultrasound showed neither evidence of renal angiomyolipoma nor renal, hepatic, or pancreatic cysts. Full-field electroretinogram (ERG) scans, which were obtained from both eyes following the protocol of the International Society for Clinical Electrophysiology of Vision, ${ }^{4}$ were consistent with retinitis pigmentosa (RP). These findings, in the context of parental consanguinity, led us to recommend a genetic evaluation in search of a genetic cause for the patient's condition. However, the patient declined molecular evaluation. During the subsequent 24 month follow-up period there was no change in fundal appearance or vision, but the results of visual field tests revealed mild deterioration. Poor visual acuity and visual field findings were attributed to RP and the thinning of the foveal area in both eyes. Amblyopia had a major contribution in the left (exotropic) eye as well. Owing to several factors present in this patient, the authors believe a conclusion could not be made regarding the specific role of the lesions on BCVA or visual field findings.

\section{Discussion}

An association between astrocytic hamartomas and RP has been described previously. However, an old controversy persists concerning the nature of the mulberry-like lesions of the optic disc in patients with RP. ${ }^{5}$ While several clinical reports have referred to them as astrocytic hamartomas, ${ }^{6-9}$ histopathological reports have often shown these to be simple optic nerve head drusen (ONHD). ${ }^{5,10}$ Puck et al ${ }^{10}$ described the pathological findings of enucleated eyes from a 22-year-old female with RP who had died in a car accident. Their conclusion was that the single, half-disc-sized, peripapillary calcified "white lesion" seen only in the right eye was giant drusen and not astrocytic hamartoma. Novack and Foos ${ }^{5}$ described a 66-year-old female with RP who had died of congestive heart failure. She had multiple bilateral small lesions over both optic nerves proven histologically to be drusen and not glial proliferations. These rare reports, although thorough, were published before the OCT era and therefore lacked OCT imaging. Moreover, the funduscopic photographs were of low quality, making them difficult to interpret. The histological findings, although both interesting and convincing, were of limited clinical relevance. The present authors believe that, taken together, the clinical and OCT appearances of the lesions in the patient presented in this case report were consistent with astrocytic hamartomas, ${ }^{1}$ leading to the conclusion that these are, indeed, glial proliferations rather than ONHD. Moreover, while visual field loss due to ONHD has been described previously, ${ }^{11}$ it more frequently involves the lower nasal quadrant ${ }^{12}$ and visual acuity is well preserved; ${ }^{13}$ both are not the case in this patient. Finally, ERG of patients with ONHD has been shown to be normal. ${ }^{14}$ Taken together, the authors believe that ONHD was not the correct diagnosis in this patient. However, given that histological examination of the lesions was not performed, the possibility that these were simply drusen 
could not be excluded. Other important diagnostic tools such as autofluorescence (AF) might have helped to differentiate between ONHD and astrocytic hamartoma (eg, while ONHD will show strong $\mathrm{AF},{ }^{15}$ an astrocytic hamartoma will show blockade of the physiologic background AF, if type 1). ${ }^{16}$ In the authors' case, unfortunately, AF was not performed.

Ulbright et al ${ }^{17}$ reviewed 42 histologically proven astrocytic tumors of the retina and found that $29 \%$ were not associated with phacomatoses. However, the presence of multiple astrocytic tumors only occurred in one patient in the sporadic group.

\section{Conclusion}

In this case report, the authors present a patient with a clinical diagnosis of multiple bilateral presumed astrocytic hamartomas, supported by high-quality imaging, in an otherwise systemically healthy RP patient. The differential diagnosis of ONHD could not be excluded.

\section{Disclosure}

The authors report no conflicts of interest in this work.

\section{References}

1. Shields CL, Benevides R, Materin MA, Shields JA. Optical coherence tomography of retinal astrocytic hamartoma in 15 cases. Ophthalmology. 2006;113(9):1553-1557.

2. Shields JA, Shields CL. Atlas of Intraocular Tumors. Philadelphia: Lippincott Williams \& Wilkins; 1999.

3. Nyboer JH, Robertson DM, Gomez MR. Retinal lesions in tuberous sclerosis. Arch Ophthalmol. 1976;94(8):1277-1280.
4. Marmor MF, Fulton AB, Holder GE, Miyake Y, Brigell M, Bach M ISCEV Standard for full-field clinical electroretinography (2008 update). Doc Ophthalmol. 2009;118(1):69-77.

5. Novack RL, Foos RY. Drusen of the optic disk in retinitis pigmentosa. Am J Ophthalmol. 1987;103(1):44-47.

6. Bec P, Mathis A, Adam P, Maillard P, Alberge Y. Retinitis pigmentosa associated with astrocytic hamartomas of the optic disc. Ophthalmologica. 1984;189(3):135-138.

7. Robertson DM. Hamartomas of the optic disk with retinitis pigmentosa. Am J Ophthalmol. 1972;74(3):526-531.

8. DeBustros S, Miller NR, Finkelstein D, Massof R. Bilateral astrocytic hamartomas of the optic nerve heads in retinitis pigmentosa. Retina. 1983;3(1):21-23.

9. Pillai S, Limaye SR, Saimovici LB. Optic disc hamartoma associated with retinitis pigmentosa. Retina. 1983;3(1):24-26.

10. Puck A, Tso MO, Fishman GA. Drusen of the optic nerve associated with retinitis pigmentosa. Arch Ophthalmol. 1985;103(2):231-234.

11. Auw-Haedrich C, Staubach F, Witschel H. Optic disk drusen. Surv Ophthalmol. 2002;47(6):515-532.

12. Savino PJ, Glaser JS, Rosenberg MA. A clinical analysis of pseudopapilledema: II. Visual field defects. Arch Ophthalmol. 1979;97(1): 71-75.

13. Grippo TM, Shihadeh WA, Schargus M, et al. Optic nerve head drusen and visual field loss in normotensive and hypertensive eyes. J Glaucoma. 2008; 17(2):100-104.

14. Mustonen E, Sulg I, Kallanranta T. Electroretinogram (ERG) and visual evoked response (VER) studies in patients with optic disc drusen. Acta Ophthalmol (Copenh). 1980;58(4):539-549.

15. Mustonen E, Nieminen H. Optic disc drusen: a photographic study; I. Autofluorescence pictures and fluorescein angiography. Acta Ophthalmol (Copenh). 1982;60(6):849-858.

16. Mennel S, Meyer CH, Eggarter F, Peter S. Autofluorescence and angiographic findings of retinal astrocytic hamartomas in tuberous sclerosis. Ophthalmologica. 2005;219(6):350-356.

17. Ulbright TM, Fulling KH, Helveston EM. Astrocytic tumors of the retina: differentiation of sporadic tumors from phakomatosis-associated tumors. Arch Pathol Lab Med. 1984;108(2):160-163.
Clinical Ophthalmology

\section{Publish your work in this journal}

Clinical Ophthalmology is an international, peer-reviewed journal covering all subspecialties within ophthalmology. Key topics include: Optometry; Visual science; Pharmacology and drug therapy in eye diseases; Basic Sciences; Primary and Secondary eye care; Patien Safety and Quality of Care Improvements. This journal is indexed on

\section{Dovepress}

PubMed Central and CAS, and is the official journal of The Society of Clinical Ophthalmology (SCO). The manuscript management system is completely online and includes a very quick and fair peer-review system, which is all easy to use. Visit http://www.dovepress.com/ testimonials.php to read real quotes from published authors. 